Benchmark

\title{
Microgel Assessment of Nucleic Acid Integrity and Labeling Quality in Microarray Experiments
}

BioTechniques 32:312-314 (February 2002)

J.M. Lage, S. Hamann, O. Gribanov, J.H. Leamon, T. Pejovic, and P.M. Lizardi Yale University School of Medicine, New Haven, CT, USA

cDNA microarrays are powerful tools for the study of gene expression profiling. Although many aspects of microarray methodology have now become standardized, the success or failure of a given experiment often depends on the quality of the labeled material used for hybridization. Since microarrays represent a considerable laboratory expense, accurate assessment of labeling quality before hybridization can result in substantial savings in both time and money. Despite these benefits, most of the techniques currently in use to evaluate the quality of labeled nucleic acids have practical limitations. The concentration of fluorescent dyes incorporated into cDNA can be measured spectrophotometrically, but this method requires substantial quantities of labeled material for accurate measurement, often a large fraction of the sample. While this material may be hybridized after measurement, some degree of photobleaching may occur, and the possibility of cross-contamination cannot be ruled out. Additionally, this method gives no insight as to the quality of labeled cDNA. Information about the size distribution of labeled cDNA can be particularly valuable when labeling tissue samples that may have undergone fixation, or when the
cDNA is derived from small numbers of cells obtained by laser microdissection, where RNA integrity tends to show variability from sample to sample.

We have developed a PAGE microgel ideally suited for the assessment of labeled cDNA quality. In contrast to previously described agarose-based microgels $(7,8)$, this simple PAGE system is optimized for the rapid analysis of fluorescently labeled DNA and does not require staining/destaining steps. A standard glass microscope slide $(75 \times$ $25 \mathrm{~mm}$ ) serves as the backplate for the microgel, and the spacers are constructed from double-sided adhesive $40 \times 20$ mm Easiseal (Hybaid, Middlesex, UK). The spacers are used to adhere the front plate (a standard glass $24 \times 40-\mathrm{mm}$ coverslip) to the backplate (Figure 1A). To cast the gel, $6 \%$ acrylamide solution is prepared following a standard nondenaturing PAGE recipe (6). A multi-well comb, cut from a thin strip of plastic, is inserted at the top of the casting. The microgel is placed horizontally, and the gel matrix (typically less than $300 \mu \mathrm{L}$ ) is poured at the bottom. After polymerization is complete (typically 30-40 min), the comb is removed, and the wells are washed with a capillary pipet.

To load the microgel, the slide is placed in an upright position inside a transparent container filled with a small amount of $1 \times$ TBE. One microliter of each sample is diluted 1:1 with loading buffer, $0.5 \mu \mathrm{L}$ are loaded in each well, and a 100-bp fluorescent DNA ladder (Bio-Rad Laboratories, Hercules, CA, USA) is loaded into an additional well. After loading, the microgel is placed in a horizontal electrophoresis unit. To provide adequate conductivity, two fil- ter paper strips are cut, soaked into $1 \times$ TBE buffer, and placed in contact with the ends of the gel (Figure 1B). The electrophoresis unit is covered with aluminum foil to protect the gel from ambient light, and electrophoresis takes place for $5 \mathrm{~min}$ at $300 \mathrm{~V}$. In a typical experiment, 50-100 $\mu \mathrm{g}$ total RNA are labeled, and $0.5 \%$ of the material is loaded on the microgel. Thanks to the high sensitivity of microarray scanners, smaller samples of labeled RNA, such as those generated by transcriptional amplification of a small number of cells, can be analyzed on microgels by loading only $1 \%-2 \%$ of the material.

In an exemplary application, we used the microgel to assess the quality of four labeling reactions prepared using two different RNA purification methods. All samples consisted of total RNA isolated from human colon tissue with TRIzOL ${ }^{\circledR}$ reagent (Invitrogen, Carlsbad, CA, USA) using an OMNI 2000 homogenizer (OMNI International, Warrenton, VA, USA). Additionally, two of the samples were further purified with the RNeasy ${ }^{\circledR}$ Mini Kit (Qiagen, Valencia, CA, USA) according to the RNeasy Mini protocol for RNA cleanup. RNA samples were quantified by the RiboGreen ${ }^{\circledR}$ assay (Molecular Probes, Eugene, OR, USA), and $100 \mu \mathrm{g}$ RNA were labeled with either Cy3- or Cy5-dUTP (Amersham Biosciences, Piscataway, NJ, USA), as described in Reference 2. An aliquot representing $0.5 \%$ of the labeled material was applied to the microgel and subsequently analyzed in an ArrayWoRx ${ }^{\mathrm{TM}}$ microarray scanner (Applied Precision, Issaquah, WA, USA). Slides were scanned at $685 \mathrm{~nm}$ (Cy5 sample), $595 \mathrm{~nm}$ (Cy3 sample), and 517 
nm (FITC-labeled DNA ladder) wavelengths with an exposure time of 0.5 s/channel. Alternatively, microgel scans can be performed using a GenePix ${ }^{\mathrm{TM}}$ 4000B scanner (Axon Instruments, Union City, CA, USA), which limits the analysis to two wavelengths, precluding the visualization of the FITC-labeled DNA ladder marker.

The microgel system readily detected differences in size distribution and fluorescence intensity between the labeled samples (Figure 2). cDNA derived from colon RNA, additionally purified with the RNeasy Mini Kit (lanes 1 and 2) exhibited greater apparent product length (50-1000 bases) when compared to products from lane 3 and 4 (50-350 bases). Kodak ${ }^{\circledR}$ 1D Image Analysis Software (Eastman Kodak, Rochester, NY, USA) was used to calculate the fluorescence intensities of each sample. The mean Cy5 intensity for lane 1 (1614.8 U) was 2.25 times greater relative to lane $3(715.29 \mathrm{U})$, and the mean $\mathrm{Cy} 3$ intensity for lane 2 (9154.9 U) was 5.71 times greater relative to lane 4 (1603.4 U). The reduced labeling efficiency in solely TRIzOLextracted samples was possibly caused by carbohydrate contamination.

The correlation between the microgel assay results and hybridization signal intensity was demonstrated by hybridizing the remaining labeled material to human 4.6-kDa poly-L-lysine cDNA microarrays (Yale Keck Microarray Facility) according to the Childs/Kucherlapati protocol (1) (http://sequence.aecom.yu.edu/ bioinf/microarray/protocol4.html). The slides were subsequently analyzed by a GenePix 4000A scanner (Axon Instruments). As predicted by the microgelsystem, the signal of TRIzOL/RNeasytreated material is considerably more intense in both $\mathrm{Cy} 3$ (4.26 times greater)

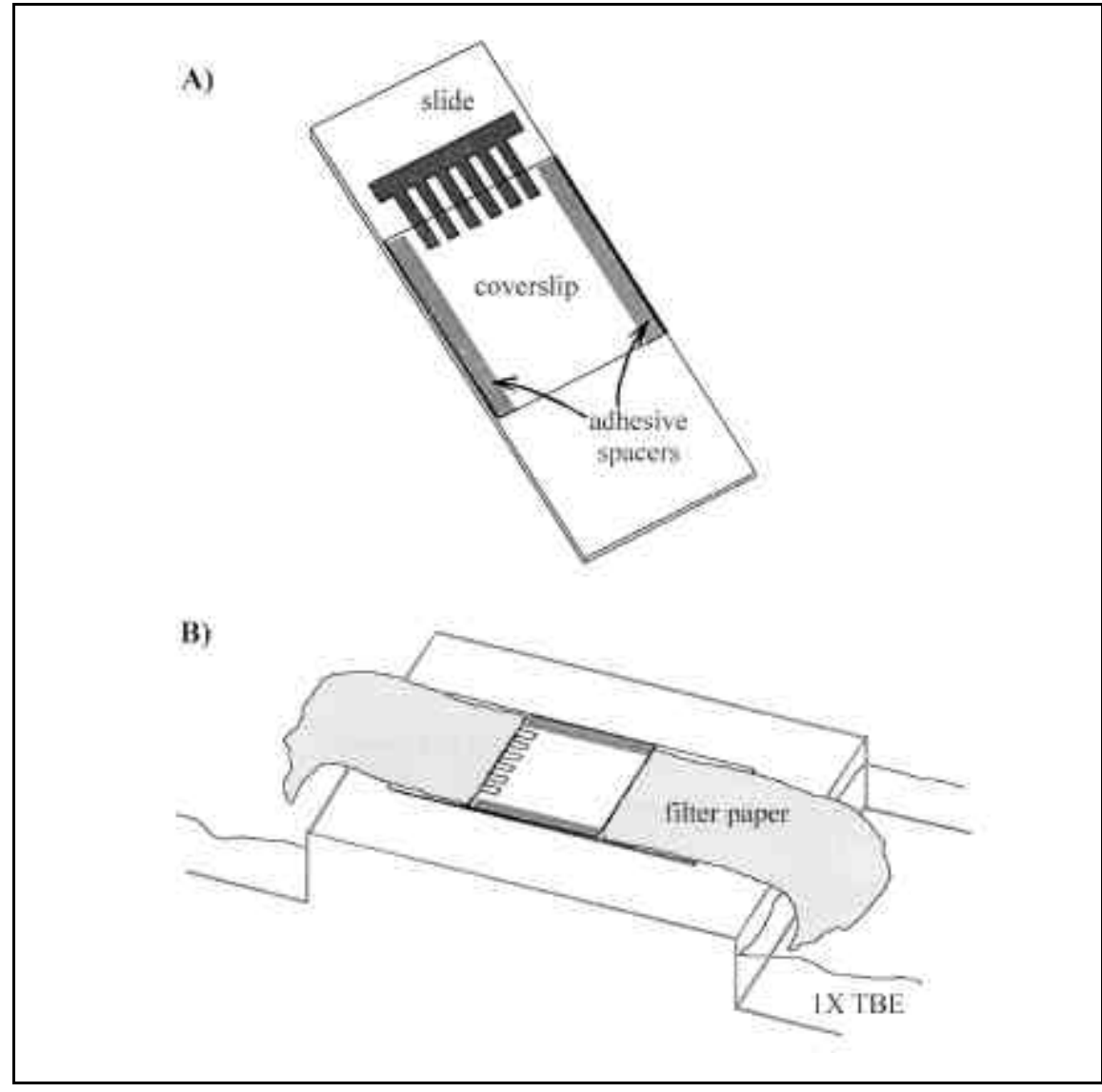

Figure 1. Schematic depiction of a mounted microgel (A) and electrophoresis (B). Microgels are mounted using double-sided adhesive spacers. The polyacrylamide mixture is poured with the microgel in a horizontal position. Once polymerized, the microgel is immersed in $1 \times \mathrm{TBE}$ buffer, and the samples are loaded in an upright position. Finally, the loaded microgel is placed over an electrophoresis tray, and wet strips of filter paper connect both ends of the microgel with the electrophoresis buffer. and Cy5 channels (3.99 times greater) than the signal from RNA purified exclusively with TRIzOL (Figure 3.). Background subtracted median intensity per pixel for the TRIzOL/RNeasy material was 754 and 607 for Cy3 and Cy5, respectively, while the median intensities per pixel were 177 and 152 for $\mathrm{Cy} 3$ and Cy5 for TRIzOL alone. Increased signal intensity has been shown to reduce variability between replicated spots on a microarray (3).

In a different series of experiments, we used microgels to evaluate the labeling quality of fluorescent samples generated by random priming of human genomic DNA using Klenow large fragment DNA polymerase. After microgel analysis, several different $\mathrm{Cy} 3$ and Cy5-labeled DNA preparations were used for comparative genomic hybridization on microarrays (arrayCGH) $(4,5)$. The array-CGH results showed a clear correlation between the labeling quality assessment based on the microgel system and the fluorescence signal intensity of the spots obtained after hybridization and scanning of the arrays (data not shown).

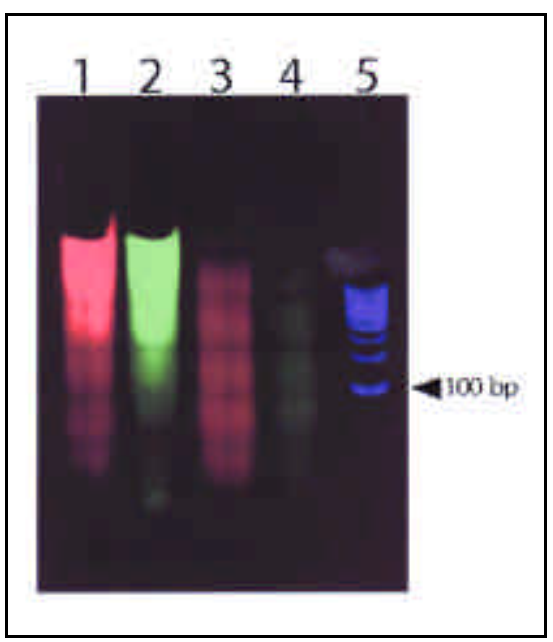

Figure 2. Microgel analysis of four fluorescently labeled cDNAs. Microgel after $5 \mathrm{~min}$ of electrophoresis at $300 \mathrm{~V}$ in $1 \times$ TBE buffer. Lanes 1 and 2 correspond to RNA purified with TRIzOL reagent and RNeasy, subsequently labeled with Cy3- and Cy5-dUTP, respectively. Lanes 3 and 4 correspond to RNA isolated exclusively with TRIzoL reagent and labeled with Cy3- and Cy5-dUTP, respectively. Lane 5 contains a 100-bp fluorescein ruler (Bio-Rad Laboratories) that was visualized in the FITC channel. Unincorporated label is not present because it has been removed by a previous Microcon ${ }^{\circledR}$ YM-30 (Millipore, Bedford, MA, USA) centrifugation step. 


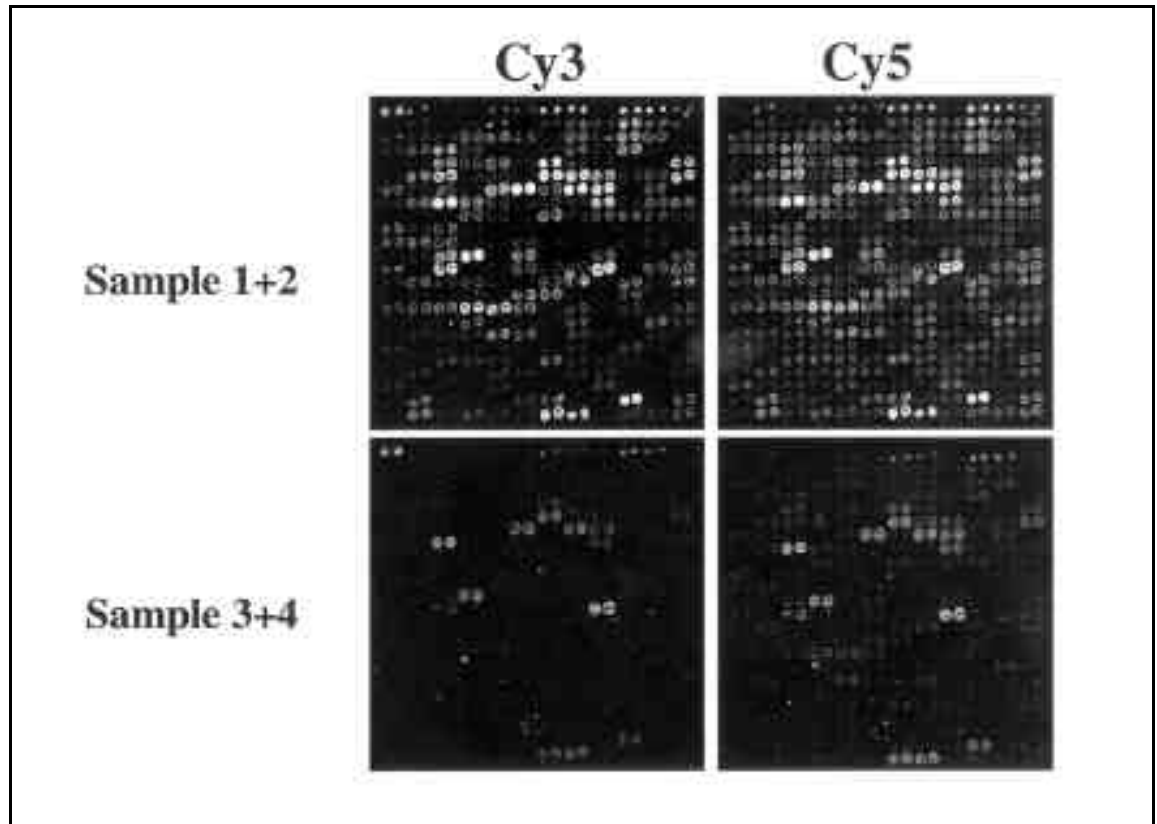

Figure 3. Comparison of signal quality between TRIzoL/RNeasy and TRIzoL-derived cDNAs. Human RNA from colon tissue was isolated with a TRIzoL/RNeasy combination (samples 1 and 2) or TRIzOL reagent alone (samples 3 and 4) and labeled with Cy3- or Cy5-dUTP, respectively. After assessing the labeling quality by microgel analysis, the microarray slides were hybridized and washed according to the Childs/Kucherlapati protocol (1). The figure shows two different $24 \times 24$ spot subarrays of a human 4.6$\mathrm{kDa}$ cDNA microarray printed on poly-L-lysine-treated slides. DNA spots for each cDNA clone are printed in duplicate.

Our cumulative experience with cDNA and genomic DNA sample labeling can be summarized as follows. Some microgel profiles of labeled material reveal intense fluorescence incorporation in very small DNA with a size distribution of 10-50 bases. This material indeed contains a fairly large amount of incorporated fluorescence label but nevertheless fails to yield strong fluorescence signals on microarrays. On the other hand, other labeled DNA preparations yield material of fairly large size (50-1000 bases) but relatively low fluorescence intensity, as judged by the microgel image. This material, which contains relatively low levels of incorporated fluors, also fails to yield sufficient signal intensity on the microarrays. Thus, high incorporation and sufficiently large chain length (>50 bases, extending to at least 300 bases) are both required for successful experiments using cDNA microarrays.

In conclusion, microgel electrophoresis of labeled samples, coupled with imaging using standard microarray scanners, is a valuable quality control for microarray experiments. This meth-

craray hybridization success. Microgels are particularly valuable for assessing labeling quality in material obtained by laser capture microdissection, yields often lead to failures in microarray experiments. Adoption of this sim ple technique can result in increased data quality and save valuable resources.

\section{ACKNOWLEDGMENTS}

J.M.L. and S.H. contributed equally to this work. This work was supported by National Institutes of Health grant no. R33CA81671 to P.M.L.

\section{REFERENCES}

1.Cheung, V.G., M. Morley, F. Aguilar, A. Massimi, R. Kucherlapati, and G. Childs. 1999. Making and reading microarrays. Nat. Genet. 21(1 Suppl):15-19.

2.Eisen, M.B. and P.O. Brown. 1999. DNA arrays for analysis of gene expression. Methods Enzymol. 303:179-205.
3.Geiss, G.K., R.E. Bumgarner, M.C. An, M.B. Agy, A.B. van 't Wout, E. Hammersmark, V.S. Carter, D. Upchurch et al. 2000. Large-scale monitoring of host cell gene expression during HIV-1 infection using cDNA microarrays. Virology 266:8-16.

4.Pinkel, D., R. Segraves, D. Sudar, S. Clark, I. Poole, D. Kowbel, C. Collins, W.L. Kuo et al. 1998. High-resolution analysis of DNA copy number variation using comparative genomic hybridization to microarrays. Nat. Genet. 20:207-211

5.Pollack, J.R., C.M. Perou, A.A. Alizadeh, M.B. Eisen, A. Pergamenschikov, C.F. Williams, S.S. Jeffrey, D. Botstein, and P.O. Brown. 1999. Genome-wide analysis of DNA copy-number changes using cDNA microarrays. Nat. Genet. 23:41-46.

6.Sambrook, J., E.F. Fritsch, and T. Maniatis. 1989. Molecular Cloning: A Laboratory Manual, vol. 1. CSH Laboratory Press, Cold Spring Harbor, NY.

7.Singh, N.P., M.T. McCoy, R.R. Tice, and E.L. Schneider. 1988. A simple technique for quantitation of low levels of DNA damage in individual cells. Exp. Cell Res. 175:184-191.

8.Singh, N.P. 2000. Microgels for estimation of DNA strand breaks, DNA protein crosslinks and apoptosis. Mutat. Res. 20:111-127.

Received 24 August 2001; accepted 4 December 2001.

Address correspondence to:

Dr. Paul M. Lizardi

Department of Pathology

Yale University School of Medicine

310 Cedar Street

New Haven, CT 06510, USA

e-mail: paul.lizardi@yale.edu where RNA degradation or low cDNA
For reprints of this or any other article, contact Reprints@BioTechniques.com 